\title{
ИЗУЧЕНИЕ СЕЙСМИЧЕСКИХ ВОЛНОВЫХ ПОЛЕЙ В ТРАНЗИТНЫХ ЗОНАХ
}

Хайдуков В.Г., Чеверда В.A.

(Институт Нефтегазовой Геологии и Геофизики СО РАН)

В работе численным методом конечных разностей исследуются вопросы распростране-ния упругих волн в неоднородной ледяной пластине, лежащей на тонком же слое воды. Подобная ситуация моделирует технологию сейсмических наблюдений в транзитных зонах.

Введение. Одной из отличительньт особенностей северных территорий России является наличие обширньх плошадей, покрытых неглубокими водоемами. Это делает затруд-нительным проведение работ в летний период. В зимнее же время на этих водоемах устанавливается достаточно мощный ледяной покров, который позволяет использовать наземные невзрывные источники сейсмических колебаний, что делает процесс проведения работ значительно более технологичным. Однако, как показывает накопленный опыт, при расположении источников на льду, регистрируемое на поверхности волновое поле оказы-вается осложненным интенсивными помехами (Рис.1б), в то время как при расположении источников на суше этих помех не наблюдается (Рис.1a).
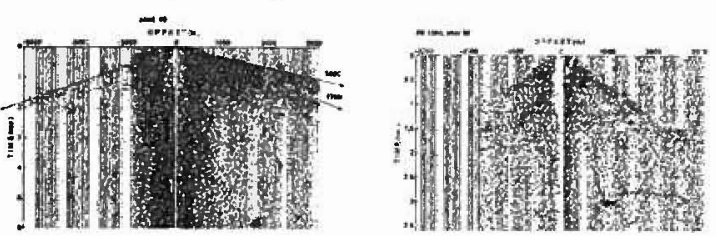

Рис.1. Примеры полевых сейсмограмм, полученных в зимнее время на Тазовской губе.

Изучение упругих колебаний стальной пластины в вакууме было проведено еще Лэмбом в начале прошлого века. В дальнейшем оно было продолокено в некоторых работах, из которых наиболее близкими к рассматриваемой постановке представляются работы $[1,2]$, посвященные изучению упругих колебаний однородной пластины, погруженной в воду. Как следует из приведенных в этих работах результатов, спецификой волновьх полей, распространяюшихся в тонком упругом слое, подстилаемом жидкостью, является наличие двух основных мод колебаний, симметричной и антисимметричной. Симметричная мода обладает скоростью близкой к скорости продольной волны во льду, имеет почти горизонтальный вектор поляризации и не диспергирует в процессе распространения. Антисимметричная же связана с изгибной волной и поляризована почти вертикально. Эта волна является чрезвычайно низкоскоростной и обладает сиљной дисперсией в процессе распространения.

Метод и результаты. Для численного моделирования использовалась специальная реали-зация конечно-разностного метода, разработанная в ИНГГ СО РАН. Результаты расчетов полного волнового поля, выполненные на пиоско-параллельных моделях, очень хорошо согласуются с результатами, полученными в упомяутых работах, и дают возможность правильно оценить параметры сеток. Однако,

результаты расчетов выполненных для реалистичной модели среды изучаемого региона с учетом рельефа дна, глубины водоема и зоны промерзания, предоставленњь специалистами ООО "ЯМАЛIЕОФИЗИКА" не дают той волновой картины, которая характерна при наблюдениях в транзитныт зонах. Следует заметить, что рельеф нижней границы льда и глубины водоема были получены по промерам с двухсотметровым интервалом и являются довольно гладкими. Поэтому возникло предположение о том, что граница ледяного покрова не является такой уж гладкой вследствия различных физических и биологических процессов, происходящих в водоеме. Расчеты, проведенные для моделей со случайновозмущенной границей льда дают результаты (рис.2.б), подобные тем, что наблюдаются на реальньх данных. Амплитуда возмущения составляла 10 см. (один шаг сетки) на интервале 4м.

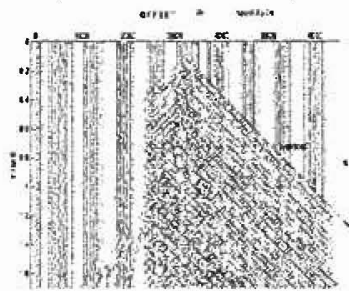

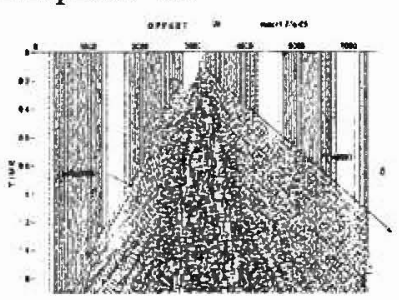

6

Рис.2. Результат численного моде.тирования для возмущенной реатистичной моде.ти, а - горизонтатьная компонента, б - вертнкатьная компонента.

Заключение и выводы. Наиболее вероятной причиной возникновения на вертикальной компоненте интенсивной случайно-коррелированной помехи при постановке сейсмических наблюдений с возбуждением и регистрацией на льду является шероховатость нижней поверхности ледового покрова. Механизм ее возникновения состоит в первоначальном возбуждении интенсивной медленной асимметричной моды, которая на неровностях льда конвертируется в интенсивнуко быстро распространяющуюся симметричную моду (рис.2а). В свою очередь, эта волна вновь трансформируется в антисимметричную моду все на тех же неоднородностях Таким образом, происходит своего рода многократная трансформашщя одной моды в другую. Подробно изучены альтернативные методы возбуждения и регистрации сейсмического волнового поля.

Настоянщая работа выполнялась по хоздоговору с ООО" "ямалгеофизика" и при частичной поддержке РФФИ, проекты 04-05-64177 и 05-05-64277. ЛИТЕРАТУРА

Осборн М. Харт С., 1953, Распространение экспоненциального импульса в статьной пластине, погруженной в воду: Вопросы сейсмической разведки, ИЛ, Москва, с. 57-63.

Исакович М.A. 1973, Общая ахустика: Наука, Москва, 348 с. 